\title{
Intermodal Mobility Hubs and User Needs
}

\author{
Daniel Bell \\ Apptec Ventures-FACTUM, Slamastrasse 43, 1230 Vienna, Austria; daniel.bell@factum.at; \\ Tel.: +43-676-407-090-2
}

Received: 30 November 2018; Accepted: 1 February 2019; Published: 20 February 2019

\begin{abstract}
Technological innovation in the mobility and transport sphere is still strongly aimed at vehicle- or infrastructure-based systems. Actual user needs in regard to accessibility and usability of the links between different transportation modes are usually addressed by standardized planning processes. In a row of four consecutive Austrian research projects, every element in the chain of intermodal routes was addressed, starting from the user-centered features of public transport stops in both urban and rural transport systems, to the planning tasks involved in providing demand-driven public transport. The current iteration focuses on establishing a typology of intermodal mobility hubs, including a differentiated view of the potential users of a multimodal transport system and their respective needs at the station.
\end{abstract}

Keywords: user need analysis; public transport; intermodal mobility

\section{Introduction}

Dynamic transport management in urban and rural areas is generally based on complex accessibility models which commonly focus on the intermediate aspects of mobility demand (Hiess et al. 2017). Accessibility and usability of the transport stop as a prerequisite for multimodality is only becoming a focus of the planning process as demand for barrier-free mobility is increasing (Chakwizira 2009; Litman 2010). In this context, the objective of the present study was to interlace recent findings on acceptability and user demand with current developments in systemic traffic planning.

Participatory processes and citizen involvement are becoming commonplace, especially in the context of sustainable development and infrastructural development processes-with varying methodological approaches and practical success (Wright et al. 2010). These approaches are usually strongly dependent on the samples of participants, the research questions, and how the process is interlinked with the other development stages of the respective projects (Scherhaufer and Grüneis 2014). Especially in the context of involving stakeholders into the process of adapting existing infrastructures, public spaces and areas of cohabitation participatory research are essential for the sustainable success of new interventions (Töpfer 2005). Most of the projects apply a state-of-the-art inventory of qualitative social research methods (including workshops, iterative citizen consulting sessions, focus groups and participatory observations, etc.) for data collection and user involvement; however, they mostly address issues on a system level without paying close attention to specific interlinks of social interactions in public space. In addition, spatial planning is usually relying on available and preexisting guidelines for the planning of certain infrastructures in traffic systems based on general demand and objective demographic data. In the presented iterations of the ongoing research project, a user-centered design approach involving all relevant stakeholders ensured that potential users, planners, and system-relevant public actors were activated early on in the development process to apply participatory processes in the context of modern intermodal mobility hubs. Hence, focus was on collecting exploratory data to provide stakeholder needs to urban and spatial planners. This represents a novel interdisciplinary approach to assessing basic user demand towards facilities and services of intermodal hubs in current transport systems. 
The findings are supposed to serve as the qualitative foundation for a typology of intermodal mobility. Differentiating the demand of different user groups needs to be tied to this typology, which takes into account regionality (geographical position and settlement structure), connection quality of the available modes of transport (number, types, and general duration of usage), different user groups (numbers, seasonal differences, trip purposes, varying needs in regards to provided information and infrastructure), and provided facilities and services (addressing not only the equipment of the immediate transport station but also the facilities within walking distance).

These dimensions, hence, not only address the infrastructural aspects of intermodal hubs in different locations in the transport network but also dimensions of organization, technological innovation, and service aspects (Monzón et al. 2016). The smallest units in the system of public transport stations usually represent access points to the larger transport system and, thus, multimodality in general (Garde et al. 2014). To support all the different potential user groups and address their specific mobility needs already in the planning process requires a sound understanding and access to current empiric data. Generally, user-centered requirements at intersections of different transport modes are defined (Pitsiava-Latinopoulou and Iordanopoulos 2012) based on the organizational level, service level, cost information, and transport times and comfort aspects involving accessibility and usability for all potential users.

The goal of this paper is to present an approach of qualitative participatory processes in order to support user-centered planning and development processes of modern intermodal mobility hubs. While this approach is becoming the norm in other urban planning contexts, there is a lack of specific knowledge on how to accommodate the heterogeneous user needs into a demand-driven approach for modern intermodal hubs.

\section{Methods}

In the presented research projects, a user-centered design approach, involving relevant stakeholders, ensured that the actual needs of potential users of a public transport system were assessed early on in the development process by conducting a social space analysis and focus group discussions. The on-site observations at public transport stops yielded a set of requirements, barriers, and potential issues which need to be addressed to increase accessibility and attractivity. The main focus of the on-site observations was the collection of characteristics (i.e., usage patterns, provided facilities and services, etc.) of different types of public transport stops in order to develop a typology of accessibility and usability needs for different user groups. In the discussion rounds, potential end-users from different mobility-related backgrounds, with varying needs, living areas, and access demands, provided insight into their mobility behavior and their needs and expectations towards alternative forms of transportation based on their day-to-day experiences. Hence, the focus of the presented work was on how public infrastructures are used and experienced by different user groups by applying a people-centric approach (Pierson and Lievens 2005).

\subsection{Social Space Analysis-On-Site Observations}

Based on behavioral observation and on-site inspections user needs of the existing heterogeneous public transport, users were conflated to a general requirements catalogue. Evaluation showed that intermodal trips and trip planning are strongly dependent on the information provided at transport stops about available offerings in the immediate transport stop periphery.

The basis for selecting the observation sites were spatial differentiation concepts, which are based on approaches to assessing the collective and cultural habitus of specific spaces as social and symbolic spatial structures which can be abstracted (Bourdieu 1998; Klüter 1986); hence, focus was not only on the objective elements in public space but also how these are perceived and used by the main user groups. Based on the spatial differentiation concept of Riege (2005) - differentiating spaces based on their social and functional qualities and structures-prespecified locations in the transport system which represent all different forms of transport stops in the federal country of Salzburg regarding 
provided facilities and services were observed in regard to social interactions, existing infrastructure, access to the surrounding areas, information, and local events.

The selection of the locations for the on-site observations was based on existing statistical information about usage and geographical information about the available offerings in the immediate environments of the transport stations. Observations on-site covered communication processes among users, usage patterns of the existing infrastructure, symbols, and information reception. A specific goal was also to situate the infrastructure-based findings at the transport stations to identify potential problem areas and best practices for further analysis. The four intermodal transport hubs selected for analysis also covered all types of urban and rural contexts as well as varying usage patterns and frequencies-city center transport terminal (1), agglomeration mobility hub (2), regional park-and-ride station (3), and rural public transport access point (4). The selection of the observation sites was not based on statistical data and available social-structural aspects of geo-information platforms (Boettner 2007) but an internal discussion round with associated experts from the field of public transport and a sampling process with focus on maximum variation. By also taking the surrounding areas within walking distance into account, each type of transport station, its usage patterns and interaction processes as well as the potential relevance of the relevant offerings was characterized with different user groups in mind. The documentation of the process was carried out by the two trained researchers who took notes and filled in a semi-structured documentation sheet for the existing infrastructure.

\subsection{Focus Group Discussions}

Participatory research processes allow for an active involvement of the target groups of new measures and innovations in the context of mobility and transport already at an early development stage. In the course of the described research process, two focus group discussions showed that a differentiation between basic public transport user needs and additional demands represent an inclusive approach to defining a requirements catalogue. Based on a theoretic sampling approach (Coyne 1997) with focus on socio-demographic and mobility behavior, participants were selected based on responses from an open call to participate in local (web-) media. The recruitment process aimed at an even distribution within each group based on gender, age group $(1=18$ to 30 years, $2=30$ to 65 years, $3=65$ and older), and everyday mobility patterns, with regular usage of the public transport system (at least several times a week) being a prerequisite for participation (see Tables 1 and 2).

Table 1. Sample of focus group \#1 participants.

\begin{tabular}{|c|c|c|c|}
\hline Participant No. & Age & Gender & General Mobility Behavior (Daily Trips for Leisure, Supply and Work) \\
\hline 1 & 28 & Female & $\begin{array}{l}\text { Generally using bicycle, except in winter months use of public transport; } \\
\text { no personal car }\end{array}$ \\
\hline 2 & 32 & Male & $\begin{array}{l}\text { Bicyclist on everyday routes, business trips and bad weather mobility is } \\
\text { dominated by public transport }\end{array}$ \\
\hline 3 & 36 & Male & Urban trips by bicycle, longer distance trips by public transport \\
\hline 4 & 36 & Female & Cannot afford personal car, uses public bus system and bicycle \\
\hline 5 & 21 & Female & In good weather bicycle, all other trips with public transport \\
\hline 6 & 27 & Male & $\begin{array}{l}\text { In urban areas by bicycle, all other trips generally by car, from time to time } \\
\text { public bus }\end{array}$ \\
\hline 7 & 27 & Male & In city center a mix of bicycle, walking, and public bus \\
\hline 8 & 65 & Male & Would like to use public transport more often but generally uses private car \\
\hline 9 & 60 & Female & everything by public transport, mainly by public bus system \\
\hline 10 & 49 & Female & Mix of public transport and bicycle \\
\hline 11 & 45 & Female & During the week mainly with public transport, in summer with bicycle \\
\hline
\end{tabular}

The two discussion rounds comprised nineteen participants who were asked, based on a semi-structured discussion guideline (see Appendix A for an overview of key questions) outlining the main research questions, to discuss their experiences, attitudes, problems, and expectations towards an inclusive and comfortable transport system with focus on public transportation. The basis for 
these discussions was everyday experiences which should characterize certain situations, problems, and best practices for the research team to characterize the basic and additional demands towards intermodal hubs. Additional topics addressed accessibility, barriers, compliance of the existing infrastructure with different usage contexts, needed and provided information, and experienced events.

Table 2. Sample of focus group \#2 participants.

\begin{tabular}{|c|c|c|c|}
\hline Participant No. & Age & Gender & Mobility Behavior \\
\hline 12 & 29 & Female & Main mode of transport is bicycle, sometimes public transport \\
\hline 13 & 24 & Female & $\begin{array}{l}\text { In bad weather with public transport, uses car when parking } \\
\text { situation is comfortable }\end{array}$ \\
\hline 14 & 24 & Male & Mainly bicycle, sometimes with public transport \\
\hline 15 & 21 & Female & Bicycle use is weather-dependent, local train system on longer trips \\
\hline 16 & 25 & Male & $\begin{array}{l}\text { Mode choice is time-dependent, later at night public bus, at other } \\
\text { times a mix of bicycle and car }\end{array}$ \\
\hline 17 & 35 & Male & Regularly with local train system and bicycle \\
\hline 18 & 20 & Female & Main mode of transport is the public bus \\
\hline 19 & 32 & Male & Mainly public bus system and walking \\
\hline
\end{tabular}

The discussions were recorded with signed consent of all participants, transcribed, and analyzed based on the categorization prescribed by the research questions on the principle of a content analysis.

\section{Findings}

The main requirements on a system level are related to the centrality of the location and its relation to other stations in the transport system, the actual transport offerings on-site, and the services related to these modes as well as actual transport and mobility demand. The differentiation of the attributes of these types of transport stops and their main characteristics was derived from the results of the on-site observations. Actual user needs were collected in the course of the conducted focus group discussions with regular users of the public transport system in the research area.

\subsection{Attributes of Intermodal Transport Hubs}

The current literature shows that, generally, four different forms of intermodal hubs are represented in both planning and development plans and research projects aiming at the assessment of demand and requirements regarding public transportation (Pfaffenbichler and Vorstandlechner 2016), which were observed in the course of the social space analysis at four selected locations in Salzburg, Austria. The modern transport hub in the urban center of cities does not merely serve as a hotspot for transfers from one mode to the next on both local and supra-regional trips but is increasingly becoming a locale for activities which serve social, cultural, and leisure purposes. The ratio of commuters and tourists is high, with lower levels of daily fluctuations and demand and usage of the provided (transport) services. In these urban locations, access for pedestrians, cyclists, and e-mobility is of increasing relevance, as it is for all kinds of sharing services (kiss and ride, bike and ride, etc.). The high variety of services leads to increased needs of timely and comprehensive information to route and inform travelers with differing degrees of system knowledge.

The next level of intermodal hubs is represented by suburban mobility hubs, which serve as connection points for metropolitan agglomerations, city centers, and supra-regional transport for commuters. The main function revolves around providing access to urban centers. While these transportation stops usually are easily accessible for pedestrians and cyclists, parking space for cars is of increased importance, which is usually provided by park-and-ride facilities. Waiting times are kept low with efficiently planned intervals during rush hour of a variety of transport lines which serve the next city center. Demand levels vary based on the level of commuting during the day and potentially seasonal changes in regard to tourism. Concerning available services and facilities, these hubs are generally similar to the center hub, with a similarly high level of provided information and comfort. 
Regional centers represent interfaces between both motorized and public transportation and rural areas, and urban centers also provide the main access points to regional destinations. These hubs are usually represented by park-and-ride facilities and are used by commuters, with lower relevance for tourism, except for specific seasonally relevant areas. Provided services and facilities are usually not as important as shopping, and leisure activities and other activities are not carried out at the source location of daily trips. This also relates to the furnishings and comfort-related facilities.

The smallest and basic "unit" of intermodal hubs is generally also the main gateway to public transport in mobility systems and therefore serves as a representative for a variety of alternative forms of transportation. These public transport gateways, while also prominent in urban centers (represented by basic public bus or tram stops with minimal local facilities), are essential facilities in rural areas for a wide variety of different user groups. They provide access to mobility to mainly those user groups who do not have access to a private car (i.e., pupils, older people, people with mobility related impairments, those who cannot afford a private car, etc.). Access is mainly limited to pedestrians and cyclists and sometimes park-and-ride facilities. Traffic demand can vary based on regional tourism but is mainly on a consistently low level. Provided facilities and services are generally minimal with weather protection and basic route information.

\subsection{User Needs at Intermodal Hubs}

Results of on-site observations at different intermodal transport stops provided a set of variables which support or prohibit the use of these infrastructures by different user groups on infrastructural, service, and comfort levels. In conjunction with the focus group discussions with public transport users, this approach led to the definition of a set of needs which can support the development and evaluation of the provided facilities and services in different regional and functional backgrounds. While the different users of intermodal transport stops are very heterogeneous in view of their needs, attitudes, and expectations, two general use cases can be defined: First and foremost, basic needs must be addressed at all hubs in a transport system; beyond these basic demands, additional demand for facilities and services addresses specific user groups and use cases (see Figure 1).

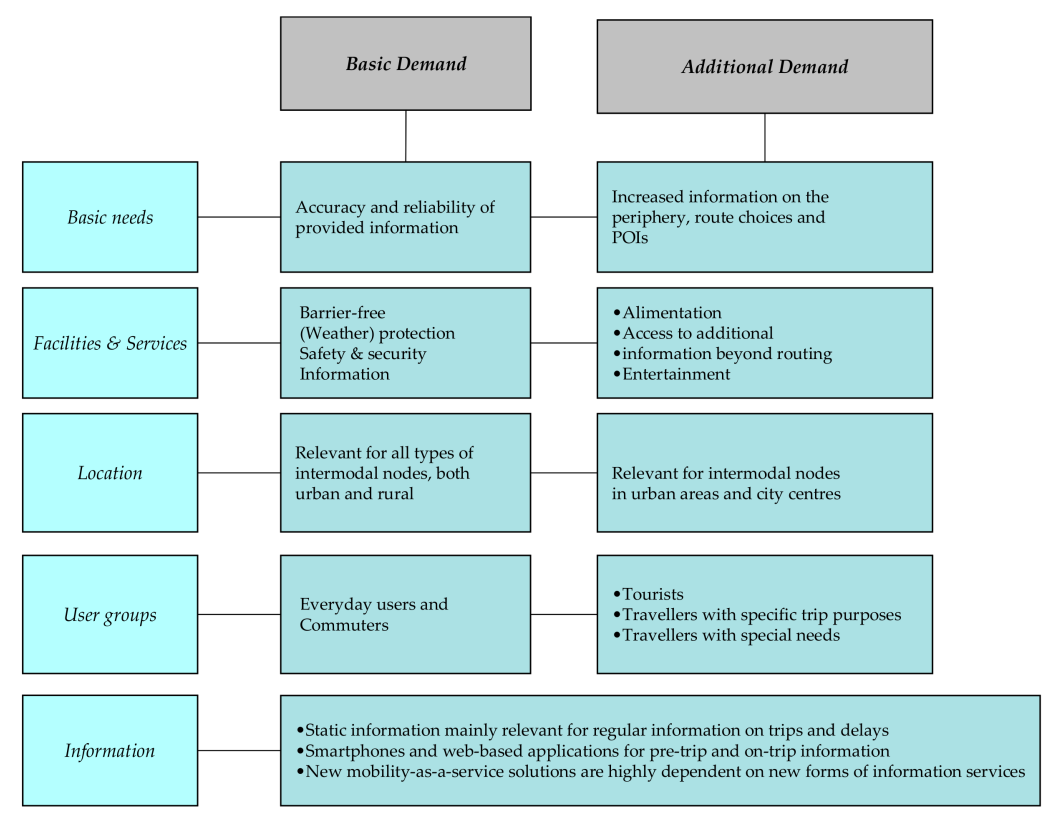

Figure 1. User requirements at public transport stops.

The basic premise of this differentiation is that if the basic needs of all user groups are met, the highest share of potential users of a public transport are provided with barrier-free access. Additional demand exists for services and facilities which increase attractivity and expand the role of 
the transport station towards other functions. Only if these additional demands are met can certain user groups and seasonal changes be convinced to change their mobility behavior.

Generally, basic demand at intermodal hubs refers to the infrastructural features and the provided services which have to ensure the safe, barrier-free, and comfortable usage of the existing facilities (including barrier-free access points to stations and platforms, waiting areas sheltered from weather, etc.). In addition, the provided information needs to be timely and reliable and accessible to all users (this also needs to include (tactile) guidance systems, suitably large and readable text information, colors and pictograms, etc.). These demands need to be addressed at all transport hubs in the system in order to make it accessible, especially to those who are limited in their physical, mental, or cognitive capabilities. These infrastructural and information-related facilities need to be supplemented with organizational and service-related measures which can support those user groups who encounter problems with modern information and guidance systems, ticketing, and orientation.

Beyond these basic needs, which ensure access and usability for all, certain demands relate to specific trip purposes and applications which affect the expectations towards facilities and services at the station and the immediate surrounding areas. While every type of intermodal hub needs to provide a specific set of information regarding the surrounding area, users who have no local knowledge, such as tourists, have a demand for a higher level of specific local information with a decreased need for exact travel times compared to day-to-day commuters. Moreover, additional demand towards infrastructure and facilities relates to information on points of interest, alimentation opportunities, and shopping, as well as seating areas which can be used for longer periods of time.

If both of these criteria are met, the intermodal hub can be transformed from a simple access point to the multimodal transport system towards a hotspot for social and leisure activities. In addition, providing sufficient facilities and services at more stations in a transport system provides users with the opportunity to plan their da-to-day trips more efficiently, leading to lower costs and times used.

\section{Discussion}

Access to intermodal mobility represents an essential aspect for ensuring inclusiveness in modern transport systems. However, user demand, seasonal and regional variations, and technological change strongly affect both the success and sustainability of the provided solutions. The relevance of different modes of transport which are accessible at an intermodal hub usually varies based on trip purpose (day-to-day trips to and from work/education, shopping, leisure activities, etc.) and the location of the station and the corresponding regional mobility demands and user groups who have varying transport demands. Recent studies on the importance of different transport mode combinations on a public transport stop which is used in the course of different day-to-day activities unsurprisingly showed that the level of intermodality (combining different modes along one transport route) is higher in densely populated urban areas compared to rural areas with fewer public transport options available (Gebhardt et al. 2016; Neumann et al. 2016).

Gebhardt et al. (2016, S. 1185-86) showed very high levels of intermodal routes for the German cities of Hamburg and Berlin (up to 10\%). Urban mobility, hence, is strongly characterized by the use of alternative means of transportation (walking, cycling) in combination with public transport. In rural areas where the public transport system is usually not as closely meshed, motorized individual transport modes are usually are of greater importance. These findings by Gebhardt et al. (2016) also show that intermodal routes are generally longer (in regard to time and distances travelled) and more complex regarding the trip purpose and the activities involved (i.e., shopping combined with leisure activities), while monomodal routes are generally used for singular purposes (i.e., drive to work, etc.). These findings clearly highlight the status of the transport station as a gateway towards sustainable multimodal mobility behavior which needs to be supported by services and offerings increasing comfort and access.

The Austrian study OPERMO (Neumann et al. 2016) defined available offerings, individual attitudes towards specific modes of transportation, and actual mobility behavior as key factors for 
multimodality based on interviews with residents of rural areas. Thus, individual assessments and expectations towards comfort, cost, and time efforts directly affect mobility decisions in both urban and rural areas (Pfaffenbichler and Vorstandlechner 2016).

The high levels of heterogeneity in regard to mobility and transport needs generally require a differentiated approach towards a set of complex profiles of requirements in a transport system. These profiles need to be differentiated based on individual sociodemographic characteristics (age, gender, stages of life and life transition points, preferred mode of transportation, place of residency, occupation, education, etc.) and include additional aspects which affect mobility behavior and respective needs (i.e., state of health, mobility impairments, etc.). Thus, mobility needs define the usability requirements of different user groups and, in turn, also significantly affect accessibility to public life.

\section{Conclusions}

While motorized individual transport is decreasing in relevance in urban areas in Austria, motorization levels are still high and expected to rise in those geographical areas where no alternative forms of transportation are provided. Sustainable development in the mobility and transport sector, however, needs to focus on decreased levels of motorized transport not only along main arteries but also in the rural areas where mobility needs and transport demand are often not met for those who are limited in their options. The results presented in this paper represent a possible approach to actively involve stakeholders in the development and planning process of transport stops in public space to ensure user needs are used as the basis for the assessment of demand-driven models. The intermodal hub represents an essential access point not only for the potential users themselves but also on a system level to increase attractivity and accessibility. The ongoing research project, in the course of focus group discussions and on-site observations at transport stops, showed that there is a high demand for improvement and adaptation. Only if the basic demand of all potential users is met-albeit with partially contrasting needs among user groups—can barrier-free access to the greater transport system beyond the private car be guaranteed. In the context of planning, these needs have to be represented on a geographical level to allow for location-based adaptations to actual demand and local user groups. The potential for taking additional demand at certain types of hubs into account provides the potential to adapt to seasonal changes and make alternative forms of transport attractive for additional user groups, by also closing the gap between the transport stop and the immediate surrounding area. While areas with a higher centrality level are usually supplied with close meshed public transport systems and innovative forms of shared mobility, these developments are lacking in rural areas, where the demand for dynamic solutions is growing.

While the presented paper provides insight into the potential of qualitative methods in the context of participatory processes to assess user needs, barriers, and issues, the generalization of the achieved results is limited. The recruitment process only yielded a limited variation in view of the planned sampling procedure; moreover, the qualitative characteristics of the whole approach aimed at a comprehensive collection of attitudes and experiences rather than representative results.

Future research needs to pay closer attention to transdisciplinary approaches, taking planning and technological innovation into account by also developing user profiles which represent the high heterogeneity level of existing needs in the context of intermodal transport. Access to empiric mobility data is growing; however, qualitative research is a prerequisite for exploring those factors which ensure long-term acceptability, usage, and hence, sustainable development at all links in modern transport systems.

Acknowledgments: This research was funded by the Austria Ministry for Transport, Innovation and Technology (BMVIT), grant number 865206 and 835747 implemented under the "Mobilität der Zukunft" program (9th call) and "ways2go" program (4th call) within proposals of the Austrian Research Promotion Agency (FFG).

Conflicts of Interest: The author declares no conflict of interest. The funders had no role in the design of the study; in the collection, analyses, or interpretation of data; in the writing of the manuscript, or in the decision to publish the results. 


\section{Appendix A. Key Questions of the Focus Group Discussions}

1. Connection between transport stop and the immediate surrounding area (including a visual stimulus/photographs of two types transport stops (modern and urban vs. basic and rural\})

2. Individual experiences in regard to the daily usage of transport stops and the connected infrastructures with focus on the following

- $\quad$ Usability (of all provided infrastructures and services)

- $\quad$ Accessibility (access to and from the transport stop)

- $\quad$ Multi-modal access (available other transport modes and parking space for cars, bikes, etc.)

- $\quad$ Facilities (toilet, vending machine, water dispenser, etc.)

- $\quad$ Safety and security (lighting, condition of the facilities, etc.)

- Information and support (departure times, schedules, maps, service personnel, etc.)

3. Discussion on the specific needs of the participants towards transport stops and provided services in the context of varying trip purposes:

- $\quad$ Preferred routes and transport modes

- $\quad$ Relevance of the surrounding area and its characteristics in the decision-making process

- Variations between leisure, work, supply, shopping trips

4. Information demand pre-, on- and post-trip

- $\quad$ Sources of information used

- $\quad$ Media used

- $\quad$ Need for special assistance

- $\quad$ Information needed (routing, points of interest, etc.)

5. Best- and worst-practices based on the experiences of the participants and the main characteristics of the discussed examples

\begin{tabular}{ll} 
- & Location \\
- & Provided facilities and services \\
\hline & Individual experiences and usage patterns
\end{tabular}

\section{References}

Boettner, Johannes. 2007. Sozialraumanalyse—soziale Räume vermessen, erkunden, verstehen. In Methodenbuch Soziale Arbeit, 2nd ed. Edited by Brigitta Michel-Schwartze. Wiesbaden: VS Verlag für Sozialwissenschaften, pp. 259-91. ISBN 978-3-531-16163-1.

Bourdieu, Pierre. 1998. Sozialer Raum, symbolischer Raum. In Praktische Vernunft. Zur Theorie des Handelns. Frankfurt a. M.: Edition Suhrkamp, ISBN 978-3-518-11985-3.

Chakwizira, James. 2009. Social Dimensions and the impact of sustainable transport and mobility on social development. In The Sustainable Transport \& Mobility Handbook, South Africa. Vol 1 (The Essential Guide). Cape Town: Alive2green, pp. 116-23.

Coyne, Imelda. 1997. Sampling in qualitative research. Purposeful and theoretical sampling: Merging or clear boundaries? Journal of Advanced Nursing 26: 623-30. [CrossRef] [PubMed]

Garde, Jan, Hendrik Jansen, and Daniel Bläser. 2014. Mobilstationen-Bausteine für eine zukunftsfähige Mobilität in der Stadt. In Proceedings REAL CORP 2014 Tagungsband. Edited by Manfred Schrenk, Vaisily V. Popovich, Peter Zeile and Pietro Elisei. Wien: Real Corp, pp. 903-7.

Gebhardt, Laura, Daniel Krajzewicz, Rebekka Oostendorp, Mirko Goletz, Konstantin Greger, Matthias Klötzke, Peter Wagner, and Dirk Heinrichs. 2016. Intermodal Urban Mobility: Users, Uses, and Use Cases. Transportation Research Procedia 14: 1183-92. [CrossRef] 
Hiess, Helmut, Thomas Dax, Luis Fidlschuster, Michael Fischer, and Theresia Oedl-Wieser. 2017. Österreichische Regionen mit Bevölkerungsrückgang-Analysen und Handlungsempfehlungen. Expert paper written in cooperation with ÖREK-working grpoup "Regionen mit Bevölkerungsrückgang”. Available online: https: / / www.rosinak.at/publikationen (accessed on 3 November 2018).

Klüter, Helmut. 1986. Raum als Element sozialer Kommunikation. Giessen: Selbstverlag des Geographischen Instituts der Justus Liebig-Universität Giessen.

Litman, Todd. 2010. Evaluating Public Transportation Health Benefits. Victoria Transport Policy Institute. For The American Public Transportation Association. Available online: http:/ / www.apta.com/resources/ reportsandpublications / Documents/APTA_Health_Benefits_Litman.pdf (accessed on 3 November 2018).

Monzón, Andrés, Sara Hernández, and Floridea Di Ciommo. 2016. Efficient Urban Interchanges: The City-HUB Model. Transportation Research Procedia 14: 1124-33. [CrossRef]

Neumann, Alexander, Alex Schubert, Michael Klamer, Georg Hauger, Tamara Vlk, Monika Wanjek, Romain Molitor, Christian Obermayer, Stéphanie Bauer-Ibili, Benjamon Kiglicim, and et al. 2016. Published project report Final Report, OPERMO-Operationalisierung der Multimodalität im Personenverkehr in Österreich. Mobilität der Zukunft, Ausschreibung 2012. Bundesministerium für Verkehr, Innovation und Technologie, Wien. Available online: https://www2.ffg.at/verkehr/file.php?id=788 (accessed on 3 November 2018).

Pfaffenbichler, Paul, and Fabian Vorstandlechner. 2016. Einfluss Innovativer Konzepte und Mobilitätsdienstleistungen auf das Angebot und die Nutzung des öffentlichen Raums in Urbanen Strukturen (IKARUS). Available online: http:/ / www.wua-wien.at/images/stories/publikationen/studie-ikarus.pdf (accessed on 3 November 2018).

Pierson, Jo, and Bram Lievens. 2005. Configuring Living Labs for a 'Thick' Understanding of Innovation. Ethnographic Praxis in Industry Conference Proceedings 1: 114-27. [CrossRef]

Pitsiava-Latinopoulou, Magdalini, and Panagiotis Iordanopoulos. 2012. Intermodal Passengers Terminals: Design Standards for Better Level of Service. Procedia-Social and Behavioral Sciences 48: 3297-306. [CrossRef]

Riege, Mario. 2005. Zur Analyse sozialer Räume: ein interdisziplinärer Integrationsversuch (Analysis of social spaces: an interdisciplinary attempt at integration). In Sozialraumanalyse: Grundlagen-Methoden-Praxis. Edited by Marlo Riege and Herbert Schubert. Wiesbaden: VS Verl. für Sozialwiss, pp. 7-68. ISBN 3-531-33604-5.

Scherhaufer, Patrick, and Heidelinde Grüneis. 2014. Herausforderungen und Grenzen partizipativer Projektarbeit—Zwei Beispiele aus der transdisziplinären Klimawandelanpassungsforschung und erste Lösungsansätze. Umweltpsychologie 18: 189-210.

Töpfer, Tobias. 2005. Stadtplanung mit Bürgerbeteiligung-Auf Dauer ein Gewinn für alle. ASA-Programm 2005; 05/01 “Agenda 21 und partizipative Stadtentwicklung". Final report.

Wright, Michael, Hella von Unger, and Martina Block. 2010. Partizipation der Zielgruppe in der Gesundheitsförderung und Prävention. In Partizipative Qualitätsentwicklung in der Gesundheitsförderung und Prävention. Edited by Michaeloettner Wright. Bern: Huber, pp. 35-52.

(C) 2019 by the author. Licensee MDPI, Basel, Switzerland. This article is an open access article distributed under the terms and conditions of the Creative Commons Attribution (CC BY) license (http:/ / creativecommons.org/licenses/by/4.0/). 